\title{
Impact of Mobile Electronic Word of Mouth (EWOM) on Consumers Purchase Intentions in the Fast-Causal Restaurant Industry in Indonesia
}

\author{
Xiangbin Yan \\ Adnan Muhammad Shah \\ Li Zhai \\ Salim Khan \\ Syed Asad Ali Shah \\ Harbin Institute of \\ Harbin Institute of Jilin University of Fina- \\ Harbin Institute of \\ Harbin Institute of \\ Technology,China. \\ Technology,China. ance \& Economics,China. Technology,China. \\ Technology,China. \\ xbyan@hit.edu.cn adnanshah486@gmail.com zhaili_hit@163.com

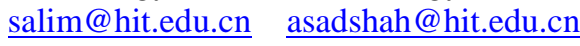

\begin{abstract}
Latest media technology may shape consumers' new motivations for disseminating word of mouth via mobile social networking sites (SNSs).This research aims to investigate the impact of social media marketing activities in terms of mobile eWOM on different dimensions of online CBBE and behavioral intentions towards online fast causal restaurant industry, using the S-O-R consumer response model. Participants ( $n=$ 351) resided in Indonesia and had prior experience of mobile application usage. SEM was used to analyze the data. The results indicate that mobile eWOM (stimulus) significantly influenced both consumer emotional, affective and cognitive responses. The emotional affective and cognitive responses significantly influenced behavioral responses. In addition, full mediation effects of CBBE were found between mobile eWOM and consumer response. Study findings emphasize the importance of examining consumer response in terms of mobile eWOM and CBBE. This study offers important theoretical and practical contributions to restaurant operators.
\end{abstract}

\section{Introduction}

With the emergence in social media, have created a new era for companies and brands in new ways to interact and engage their customers (Godey et al. 2016). With the rapid expansion in the usage of mobile devices and the advancement in wireless network are penetrating mobile services to every corner of today's life. Various mobile services including mobile commerce services (e.g. mobile health, mobile instant messaging, mobile banking and entertainment services) have been greatly changing people's way to shop, to interact, and even to live. Quick expansion in smart phone consumption is increasingly replacing traditional personal computers with the mobile applications. Many global players (e.g. amazon, ebay) have already launched the- ir mobile apps to grab their market shares (Gupta and Arora 2017; Wang et al. 2013). Since the internet is important in cost effective dissemination of information about product and services, mobile electronic word of mouth (eWOM) is consider as an influential marketing instrument in social networks context (Murtiasih et al. 2013). Before purchasing any products or service, consumers always search for that information, posted by the previous consumers on SNS. Internet provides different platforms for eWOM e.g. blogs, discussion forums, shopping / review / SM websites (Erkan and Evans 2016). Although social media provides many benefits and new opportunities for brand management, but one of the persistent challenge is the difficulty in measuring the impact of social media marketing on different measures of brand success (Ayeh et al. 2013).

EWOM has strong impact in hospitality industry. Intangibles such as restaurant services cannot be evaluated before the consumption experience; therefore, purchasing intangible products and services brings a higher risk, so customers are more dependent on the interpersonal influence of eWOM. For example, Dianping.com, a Chinese website that facilitates consumers to share their consumption experience about a restaurant or an entertainment venue. The eWOM services have been extended to the mobile context after the development of mobile technologies. Mobile eWOM services enable consumers to seek and share consumption experience in a real-time and interactive manner (Hsiao et al. 2016; Wang et al. 2013).

The eWOM and understanding of the customer behavior has become more important and useful for restaurants managers (Jeong and Jang 2011). Fastcasual restaurant is a market niche similar to the fastfood restaurant that does not offer most table services, but promises higher quality of foods and atmosphere up to some extent. As consumers are increasingly interested to taste higher-quality and healthier food, better physical eating conditions, and better customer service, the fast-casual dining segment falls between the "quick service" and "full service" segments. Approximately one-third of the restaurant operators say their customers are looking for a wider range of food 
choices from restaurants, while 19 percent say customers only seek healthy alternatives. (Ryu et al. 2010).

Previous literature has discussed the relevant issues of eWOM through PC-based SNS, while the reason behind the consumers' dissemination of information to better understand consumer behavior in the environment of mobile eWOM from the branding perspective has seldom been investigated (Godey et al. 2016; Lin et al. 2017; Wang et al. 2013). In spite of many eWOM advantages related to restaurant quality mentioned by quick-serve operators, we must emphasize the increasing importance of the fast-casual restaurant industry sector. Therefore, this study can be regarded as a try to fill this research gap by contributing to prior literature by offering a comprehensive framework that shows how mobile eWOM efforts influence consumer based brand equity (CBBE) and consumer behavior towards fast-causal restaurants in Indonesia.

To investigate the literature gap mentioned above, we formulate two research questions: 1) would mobile eWOM influence the different dimensions of CBBE in consumer mind? 2) how does CBBE affects consumer response through mobile eWOM? This study has three research objectives (1) to empirically test the impact of mobile eWOM on dimensions CBBE (2) to empirically test the relationship between $\mathrm{CBBE}$ and consumer response, and (3) to measure the relationships between mobile eWOM, dimensions of $\mathrm{CBBE}$ and consumer response. This paper is structured as follows: first, we present research background. Then, we propose our conceptual framework and study hypothesis. Finally, we discuss the methodology, results, implication and future research of our study.

\section{Research back ground}

\subsection{Emergence of mobile eWOM}

Mobile eWOM communication can be viewed as a positive or negative communication between potential, actual, or former customers about a product, service or company, which is available to the group of people and institutions through the mobile Internet and device (Wang et al. 2013). Social media communication is considered as a true and appropriate platform for mobile eWOM, because users can post about brands and their products or services on social media website (Hsiao et al. 2016). In addition to daily communication between customers, social media apps also allow people to create and promote profiles, related to different products and services. People can share their ideas and comments via pictures, videos and written texts. Visually enriched contents make mobile eWOM more attractive and appealing. Social media apps facilitate the diffusion of mobile eWOM information among the many people and users, who can even share their feelings and thoughts by only forwarding those posts they agree with (Erkan and Evans 2016; Lin et al. 2017).

Literature on modern information system research mainly focuses at the determinants of the mobile-based environment and not addressed their effect on customers yet. According to trust transfer theory, customer trust added over time in eWOM may influence customer trust in mobile eWOM. Therefore, building customer trust is critical for helping mobile eWOM to become more accepted, used and thus makes the business more successful (Lin et al. 2017; Lu et al. 2011). Impact of mobile eWOM trust on customer purchase intentions can be explained by addressing the literature on both mobile services and eWOM. According to the mobile service literature, prior research has stated trust in terms of perceived quality, information credibility and behavioral intention, because it can increase performance expectancy, perceived usefulness and attitude (Wang et al. 2013).

Although the role of trust has been examined in the context of variety of mobile services (e.g., mobile commerce or banking), but its role in the mobile eWOM services and consumer behavior has been less explored. Therefore, trust in terms of perceived quality and information credibility is a critical and challenging issue for eWOM services. In particular, the unique features of mobile services make the trust issue more prominent. Therefore, this study attempts to propose and empirically test a research model to theorize the impact of mobile eWOM trust on consumer behavior with mediating role of CBBE (Erkan and Evans 2016; Lin et al. 2017; Wang et al. 2015).

\subsection{Online CBBE and consumer behavior}

Development of the brand equity concept carried significant changes to the brand concept (Godey et al. 2016). Bruhn et al. (2012) defined CBBE as: a set of assets and liabilities attached to a brand, its name, symbol or logo that add or subtract the value provided by a product or service to a firm and its customers. These assets contain brand awareness/associations, brand loyalty, brand perceived quality and brand attitude. Brand equity benefits the online companies in several ways which has been subject to widespread debate, just as the mean of discussions. Most scholars agree that stronger brand equity can increase brand preference (Schivinski and Dabrowski 2015). Godey et al. (2016) investigated social media in the online brand equity context, that social media marketing is positively related to the purchase intention (PI). 
In the social media setting, marketing activities enhance CBBE. Social media marketing actions are part of the promotional mix in the new brand communication paradigm (Godey et al. 2016). Bruhn et al. (2012) disclosed that firm created social media communications have positive impact on brand awareness/ association and brand loyalty, while users generated social media communications have positive impact on brand awareness/association, brand loyalty, perceived quality (Schivinski and Dabrowski 2015). Based on previous studies and findings, this study used stimulus organism-response (S-O-R) framework for its own research model.

\section{Conceptual framework and hypotheses development}

\subsection{Stimulus-Organism-Response Framework}

The influence of eWOM on consumer's response can be explained as the influence of stimulus on organism and the corresponding response according to the stimulus (S)-organism (O)-response $(\mathrm{R})$ model. The organism acting as a mediator between stimulus and response shows the significant relationship between these constructs. According to the previous research, S-O-R can be used to explain the effect of external influences on consumers $(S)$, internal processes respond to that influence $(\mathrm{O})$, and the outcome as behaviors $(\mathrm{R})$ (Eroglu et al. 2003). The external influences (e.g., informational inputs) e.g. advertising, design and product price can be used as controllable factors while competition and social pressure can be included as non-controlled environmental factors. Internal processes include affective, emotional and cognitive responses in terms of arousal, fear and liking. Finally, customer intention to act includes the behavioral responses (Kim and Johnson 2016). Since the S-O-R model has been used in consumer research in various contexts. Chebat and Michon (2003) focused on variables describing traditional brick and mortar stores include music, color and lighting on consumer behaviors, e.g. purchase intentions. Juanjuan et al. (2013) found the impact of content of ad on viewing time (i.e., behavioral response) and found arousal, attitude and pleasure towards the ad that mediates the relationship between content of ad and viewing time. Researchers have also described the applicability of the S-O-R framework in the context of online shopping.

The S-O-R framework was engaged due to the constructs and their relationships among them illustrate the principal interests of this research. It stated that brandrelated mobile eWOM(S) evoke affective, emotional and cognitive response in terms of brand awareness/ association; brand loyalty; perceived quality and brand attitude $(\mathrm{O})$ within consumers, and these internal states have strong influence on the consumer's responses (R) in terms of customer purchase intentions (Kim and Johnson 2016).

Researchers explained the S-O-R models in online environment; found that purchase intention and intention to engage in WOM activities are related to eWOM (Wang et al. 2011). In addition to the basic constructs of the S-O-R model which have been discussed previously. Our model includes affective, emotional and cognitive response variables (i.e. brand awareness/ association, brand loyalty, perceived quality and brand attitude) as a component of organism because main goals for companies engagement in social media activities are not only to increase brand awareness but to build and enhance strong relationships with new and existing customers (Kim and Ko 2012). Our model proposed that information passes through mobile eWOM via SNS platform. So this model can be applied to examine the influence of mobile eWOM within an online context.

The cognitive response model defines that cognitions occur before affect. It includes beliefs, perceptions and thoughts, constructed via direct interaction with the stimulus. When a consumer exposed to stimuli e.g. eWOM that provides information about a products/services, cognitive processes must take place in order to understand the factual content presented. After understanding the stimuli, the consumer creates an affective or emotional response toward the information. According to the affective response model, a stimulus stimulates an affective state (e.g., joy, fear) prior to any cognitive response. A very little research focused on the process of consumers' purchase decision in social commerce mobile apps context. Mobile eWOM on SNS contains the consumption experiences, factual information, and affect related to a brand. As brand-related mobile eWOM shared via SNS contains both informational (brand related user generated communication), affective and cognitive emotional messages (brand awareness/association; brand loyalty perceived quality and brand attitude) (Godey et al. 2016; Ha et al. 2015; Hudson et al. 2015; Kim and Johnson 2016; Lu et al. 2011; Wang et al. 2013).

Mobile eWOM consist of three factors.1) argument quality 2) source credibility 3 ) valence. Argument quality is defined as the persuasive strength of arguments which are embedded in an informational message. Argument quality consists of two sub -dimensions. a) Argument quality relevance is defined as the extent to which the messages are applicable and useful in terms of decision making. b) Argument quality accuracy is defined as the reliability of the messages/arguments. Argument quality accuracy also represents a user's per- 


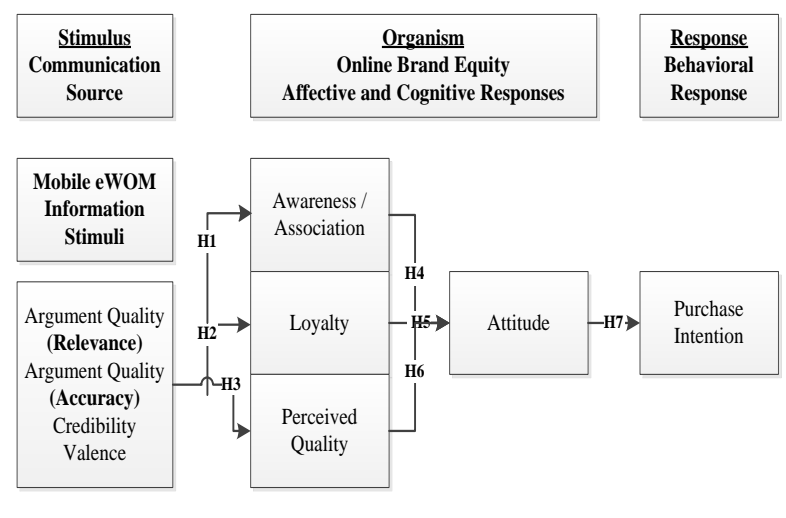

Figure 1. Theoretical model

ception that the information in online reviews is correct (Cheung and Thadani 2012).

Source credibility is an important factor on SNS. 2)Source credibility is defined as the extent to which source of information is perceived to be trustworthy, believable and competent by the receivers of information (López and Sicilia 2014). Prendergast et al. (2016) examined, how male and female differs in terms of perceived trust of positive, negative and mixed eWOM. Their results indicated that females have greater capability of trust than males when comparing eWOM messages. Both genders consider mixed eWOM as more trustworthy than positive and negative eWOM.

Using the S-O-R model in Fig. 1, researchers have suggested the effect of website stimuli on brand awareness/association. Schivinski and Dabrowski (2015) defined awareness and association as "it is the strength of a brand's presence in the mind of consumers", "brand associations consist of instances, multiple ideas, facts and episodes that comprise a network of brand knowledge". Bruhn et al. (2012) indicated that perception of communication stimuli positively influences the individual's perception about the brand. We assumed that mobile eWOM and the consumer's perception of brand awareness/association are related to each other. Therefore we propose that:

H1: There is the positive relationship between mobile eWOM and brand awareness/association

Schivinski and Dabrowski (2015) has defined brand loyalty as "a deep commitment to rebuy a preferred product or service consistently in the future, irrespective of other situational factors and marketing efforts, having the potential of switching behavior to other brands". Priori studies found that spending on advertising is positively correlated with the brand loyalty because it reinforces significant attitudes towards the brand in the framework of social media brand communication (Schivinski and Dabrowski 2015). Bruhn et al. (2012) indicated that the quality communication in brand communities have a positive impact on functional and symbolic brand community benefits, results leveraging the brand loyalty. Therefor$\mathrm{e}$, we assume the following hypothesis.

H2: There is the positive relationship between mobile eWOM and brand loyalty.

Perceived quality is the consumer's perception about the overall quality or superiority of a product or service as compared to its alternatives (Schivinski and Dabrowski 2015). Consumers generally perceive that highly advertised brands are higher quality brands. They also indicated that eWOM is an important source by which customers obtain information about the quality of products or services (Hudson et al. 2015). Thus, we propose that:

H3: There is the positive relationship between mobile eWOM and brand perceived quality.

Overall brand is evaluated and represented by the attitude towards the online fast-causal restaurants. According to the theory of reasoned action (TRA), attitude comprises of multiplicative combination of brandbased associations of attributes (Bruhn et al. 2012; Godey et al. 2016; Schivinski and Dabrowski 2015). Keeping in view the previous research and positive effect of mobile eWOM on brand awareness/association, brand loyalty and perceived quality, the overall effect of brand equity on attitude can be taken as positive (Bruhn et al. 2012).Thus we propose that:

H4: Awareness/association is positively related to attitude towards the online fast - causal restaurants.

H5: Loyalty is positively related to attitude towards the online fast - causal restaurants.

H6: Perceived quality is positively related to attitude towards the online fast - causal restaurants.

Purchase intentions (PI) is defined as "a consumer ability to purchase the products on routine basis" (Kim and Ko 2012). Most scholars agreed that stronger online CBBE contributes to positive consumer behavior (Bruhn et al. 2012). In the social media and online brand equity settings, researchers found that the social media marketing activities positively impact the consumers purchase intentions. Consumers tend to prefer product/services on the basis of what they know and feel about it (Godey et al. 2016). Kim and Johnson (2016) stated that the consumers' cognitive and emotional feelings have a strong impact on shopping outcomes. According to the attitude and behavior hypothesi$\mathrm{s}$, attitude has positive impact on purchase intentions (Bruhn et al. 2012). Thus we propose that:

H7: There is a positive relationship between attitude towards online fast-causal restaurants and purchase intentions.

In order to verify the mediating effect of organism in the S-O-R model, a mediation test was conducted. Social media strategies describe the positive consumer behavioral intentions towards online restaurant brands. 
This influence is mostly indirect, which involves the prior formation of dimensions of CBBE for online fast - causal restaurants (Jeong and Jang 2011; Kim and Johnson 2016; Sparks and Browning 2011; Xie et al. 2014). Thus we assume that:

H8: Brand equity mediates the relationship between mobile eWOM and Purchase intentions.

\section{Methodology}

Data consisted of 351 participants was collected through online web based survey questionnaire (http:// www.surveymonkey.com/). A survey hyperlink was placed on different social networking sites. The study questionnaire used 5-point likert scales, where 1 stands for "strongly disagree"till 5 stands for "strongly agree" agree". Forty five days data collection process from $25^{\text {th }}$ January to $10^{\text {th }}$ March 2017 , the survey sample demographics are shown in Table 1. Data was collecte$\mathrm{d}$ from those Indonesian consumers in capital city of Jakarta (Indonesia) who use mobile applications for online purchases, without limitation on demographics. Jakarta was chosen as sample because the population of Jakarta is more diverse. It is the capital and most populated city of Indonesia i.e. 10,075,310 people, 2014 census [35]. As the Indonesian people like to explore and try new foods of many other countries and cultures whether it is Japanese, European, American, Western, Middle Eastern food. Malls and departmental stores in Jakarta provide these essential places for people to hangout communication with each other, to try new restaurants.

As the questionnaire was translated into the Indonesian language called "Indonesian", we adopted a back translation procedure to ensure the validity of translation. First, all original items in the instrument were translated into Indonesian by a researcher whose

Table 1 Sample demographics

\begin{tabular}{lll}
\hline $\mathbf{n}=\mathbf{3 5 1}$ & $\#$ & \% \\
\hline Age (Years) & & \\
Below 18 & 32 & 9 \\
$18-35$ & 186 & 53 \\
$36-45$ & 74 & 21 \\
$46-55$ & 39 & 11 \\
56 and above & 20 & 6 \\
Occupation & & \\
Students & 84 & 24 \\
Private sector employee & 134 & 38 \\
Civil servants & 56 & 16 \\
Self-employed & 77 & 22 \\
Income & & \\
< Rp. 1.000.000 & 56 & 16 \\
Between Rp. 1.000/ - Rp. 5.000/. & 157 & 45 \\
Between Rp. 5.000/ - Rp. 10.000/. & 99 & 28 \\
> Rp. 10.000/. & 39 & 11 \\
\hline
\end{tabular}

native language was Indonesian. Another researcher then translated that instrument back to English. Further the two researchers and one professor belong to the mobile commerce industry confirmed the meaning of the Indonesian version by comparing the two English versions. We then invited a panel of experts in the field of mobile-commerce to give feedback and suggestions on measures. Finally based on their feedback, we modified the wording of those items which were not clear and understandable to them. Finally, the two initial translators rechecked the modified version of the Indonesian questionnaire. A pilot test was conducted consist of 34 users who most frequently use mobile apps for different purchases.

\section{Data analysis and results}

\subsection{Measurement model}

We used 19-items scale to measure mobile eWOM characteristics, adapted from (Cheung and Thadani 2012; Erkan and Evans 2016; López and Sicilia 2014), thirteen-item scale of online CBBE, adapted from (Allen Broyles et al. 2010; Buil et al. 2013; Rios and Riquelme 2008; Shekhar Kumar et al. 2013; Shuv-Ami 2016), five-items scale to measure purchase intentions adapted from (Park et al. 2014) (See Appendix A). Cronbach's alpha reliabilities are shown in Table 2, indicating satisfactory measuring reliability. When comparing age, occupation and income as control variable with purchase intentions using one-way ANOVA, purchase intentions differed significantly among their groups $(\mathrm{F}=3.42, \mathrm{p}<.05),(\mathrm{F}=4.580, \mathrm{p}<.05)$ and $(\mathrm{F}=$ $2.578, \mathrm{p}<.05)$ respectively. So age, occupation and income are control variables in this study.

The research model was evaluated by using AMOS 23, a structural modeling technique was used to predict models (Erkan and Evans 2016). Before testing the hypothetical relationships, we analyzed the composite reliability (CR), construct and convergent validity of the scales. Two different analyses were conducted to measure the purification. First, exploratory factor analysis (EFA) with varimax rotation was conducted on the original set of items. The Kaiser-Meyer-Olkin (KMO) measure of sampling adequacy was 0.874 and Bartlett's Test of Sphericity was significant at the 0.0001 level, indicating that the data matrix was sufficiently correlated to the factor analysis. Factor loadings greater than .60 with eigenvalues greater than 1.0 was considered to be the evidence for construct validity (Kim and Johnson 2016). This process eliminated nine items due to low factor loadings. Secondly, confirmatory factor analysis was conducted by using maximum likelihood estimation on the item correlation matrices. 
The magnitude of large modification indices (MI), item error variances, and standardized residuals values were examined. In this process, an additional fourteen items were removed. As a result of these analyses, 37 of the original 60 items were retained for testing of hypothesis. The final measures used for the data analysis were arranged by constructs (See Table 2).

To test the measurement model, confirmatory factor analysis (CFA) with maximum likelihood was conducted on the 37 indicators of the six latent constructs. The results of CFA indicated that the measurement model has acceptable construct validity. The model exhibited an excellent fit with the data: $\chi^{2}=1521.52$ with $617 \mathrm{df}, \chi^{2} / \mathrm{df}=2.466, \mathrm{p}=.000$; comparative fit index $(\mathrm{CFI})=.829$; non-normed fit index $(\mathrm{NNFI})=$ .752; standardized root mean square residual (SRMR) $=.04$; root mean square error of approximation $($ RMSEA $)=.06$. In general, CFI, NNFI values of .75 or higher and RMSEA of .060 or lower indicate a satisfactory model fit (Kim and Johnson 2016). Convergent validity was examined by using the composite reliability $(\mathrm{CR})$ and the average variance extracted (AVE). The lowest acceptable value is 0.60 for $C R$ and 0.50 for AVE of each variable. Results in Table 2, show that values of AVE are more than 0.50 which results the convergent validity is achieved (Erkan and Evans 2016). The recommended level for the factor loadings is 0.60 and all the factor loadings in this study are greater than 0.60 (See Table 2). In order to achieve discriminant validity, the square root of AVE for each variable is greater than the other correlation coefficients which represents that the discriminant validity achieved (Erkan and Evans 2016) (See Table 3).

\subsection{Results of the structural model}

The hypothesized relationships in the structural equation model (SEM) were examined by the maximu$\mathrm{m}$ likelihood estimation method. The structural model exhibits a good fit with the data $\left(\chi^{2}=1646.654\right.$ with $622 \mathrm{df}, \chi^{2} / \mathrm{df}=2.65, \mathrm{p}=.005, \mathrm{CFI}=.793, \mathrm{NNFI}=$ .706 , and RMSEA = .069). All paths related to Hypothesis 1 through 8 were statistically significant. Mobile eWOM was positively associated with three dimensions of CBBE. More specifically, H1, The influence of mobile eWOM on brand awareness/accociation was positive $(b=.896, p<.001)$. Similarly, H2, mobile eWOM has significant positive impact on brand loyalty $(b=.771, p<.001)$. Furthermore, H3, mobile eWOM has significant positive impact on brand perceived quality $(\mathrm{b}=.751, \mathrm{p}<.001)$. Further, H4, brand awareness/association has significant positive impact on attitude towards online fast-causal restaurant $(b=$ $.169,, \mathrm{p}<.001)$. H5, loyalty was found to have positi- ve influence on attitude towards online fast-causal restaurants $(\mathrm{b}=.570, \mathrm{p}<.001)$. H6, predicted the positive influence of perceived quality on the attitude towards the online fast-causal restaurants $(b=.295, p<$ $.001)$. Finally, H7, predicted that attitude towards online fast-causal restaurants positively influence purchase intentions $(b=.778, p<.001)$ (See Table 4$)$.

Participants who respond to brand related user generated communication (UGC) with emotions and pleasure, they supposed that perceived information to be useful to associate with the brand. Further regarding the effect of mobile eWOM on brand attitude as well as on purchase intention are drawn from an investigation of the indirect effects. These findings provide empirical support for the conceptual definition of CBBE stimulated by UGC and its effect on parallel response in terms of purchase intention (Bruhn et al. 2012; Godey et al. 2016; Kim and Ko 2012). In order to test the mediating effect of organism (CBBE) in the S-O-R model, a mediation test was conducted by using Baron and Kenny (1986). Organism i.e. CBBE of online fastcausal restaurants fully mediates the relationships between mobile eWOM and purchase intentions, which verifies our hypothesis H8 (See Table 4).

\section{Discussion and implications}

An increase in number of mobile marketing studies, mobile eWOM provides many opportunities and challenges for management. The influence of mobile eWOM, mobile shopping and mobile marketing in the context of consumers response has been known since long time by researchers (Ha et al. 2015; Lin et al. 2017; Lu et al. 2011; Ström et al. 2014; Wang et al. 2013; Wang et al. 2015). Researchers have been struggling to find out empirical evidence about relationship between mobile eWOM and CBBE and how this relationship affects other important branding goals, i.e. purchase intentions. This research addresses these important challenges and gaps in the literature by offering a study on consumer response towards online fast - causal restaurants in the mobile eWOM context.

Our findings indicate that mobile eWOM include emotional and information contents positively influence brand awareness/association (.89). EWOM act as informational stimuli to activate consumer's affective responses i.e. awareness/association towards the online restaurant, when participants encountered to mobile eWOM through online restaurant booking. These findings are in line with those of previous researchers (Wang et al. 2013). Godey et al. (2016) also documented that WOM through social media in terms of information stimuli significantly affect brand awareness/ /association (organism). Secondly, findings also confir- 
Table 2. Factor loadings and reliability measures

\begin{tabular}{|c|c|c|c|c|c|}
\hline Items & Loadings & Cronbach's & $\alpha$ & $\mathrm{CR}$ & AVE \\
\hline \multicolumn{2}{|c|}{ Mobile eWOM } & .632 & & .904 & .515 \\
\hline ARQ1 & .605 & & & & \\
\hline ARQ2 & .712 & & & & \\
\hline ARQ3 & .789 & & & & \\
\hline ARQ4 & .723 & & & & \\
\hline ARQ5 & .754 & & & & \\
\hline \multicolumn{6}{|c|}{ Argument Quality Accuracy } \\
\hline AQA1 & .662 & & & & \\
\hline AQA2 & .853 & & & & \\
\hline AQA3 & .714 & & & & \\
\hline AQA4 & .662 & & & & \\
\hline AQA5 & .789 & & & & \\
\hline AQA6 & .585 & & & & \\
\hline \multicolumn{6}{|c|}{ Source Credibility } \\
\hline SC1 & .689 & & & & \\
\hline $\mathrm{SC} 2$ & .754 & & & & \\
\hline $\mathrm{SC} 3$ & .751 & & & & \\
\hline $\mathrm{SC} 4$ & .614 & & & & \\
\hline SC5 & .791 & & & & \\
\hline \multicolumn{6}{|l|}{ Valence } \\
\hline V1 & .623 & & & & \\
\hline $\mathrm{V} 2$ & .641 & & & & \\
\hline V3 & .791 & & & & \\
\hline Brand Eq & & .716 & & .796 & .511 \\
\hline \multicolumn{6}{|c|}{ Awareness/Association } \\
\hline AWS1 & .634 & & & & \\
\hline AWS2 & .752 & & & & \\
\hline AWS3 & .785 & & & & \\
\hline AWS4 & .650 & & & & \\
\hline Loyalty & & .711 & & .664 & .528 \\
\hline LO1 & .753 & & & & \\
\hline $\mathrm{LO} 2$ & .712 & & & & \\
\hline LO3 & .714 & & & & \\
\hline \multicolumn{2}{|c|}{ Perceived Quality } & .671 & & .623 & .518 \\
\hline PQ1 & .652 & & & & \\
\hline PQ2 & .611 & & & & \\
\hline PQ3 & .612 & & & & \\
\hline Attitude & & .666 & & .611 & .512 \\
\hline AT1 & .751 & & & & \\
\hline AT2 & .713 & & & & \\
\hline AT3 & .682 & & & & \\
\hline \multicolumn{2}{|c|}{ Purchase Intention } & .683 & & .511 & .598 \\
\hline PI1 & .638 & & & & \\
\hline PI2 & .789 & & & & \\
\hline $\mathrm{PI} 3$ & .685 & & & & \\
\hline PI4 & .672 & & & & \\
\hline PI5 & .777 & & & & \\
\hline
\end{tabular}

med that loyalty (.77), which is emotional and affective response component of S-O-R model; mobile eWOM and customer loyalty are positively related to each other in the online fast-causal restaurants industry. The reason behind this significant relationship is explained by previous studies conducted by (Baxendale et al. 2015; Wang et al. 2013). These studies indicated that in mobile eWOM context participants were simply to review the postings on online restaurants websites and respond to comments through mobile eWOM by assessing the information. Participants were aroused by
Table 3. Descriptive statistics

\begin{tabular}{ccccccc}
\hline Construct & MEW & AWS & LO & PQ & AT & PI \\
\hline MeWOM &. $\mathbf{7 1 7}$ & \multicolumn{6}{c}{} \\
AWS & .665 & .714 & & & & \\
LO & .630 & .591 & .727 & & & \\
PQ & .552 & .496 & .480 & .720 & & \\
AT & .603 & .640 & .642 & .544 & .716 & \\
PI & .637 & .560 & .587 & .494 & .635 & .773 \\
Mean & 3.86 & 4.00 & 4.01 & 4.05 & 4.06 & 4.05 \\
SD & .447 & .682 & .649 & .648 & .563 & .555 \\
\hline Note: MeWOM=Mobile eWOM; AWS=Awareness/Asso- \\
ciation; LO=Loyalty; PQ=Perceived Quality; \\
AT=Attitude; PI=Purchase Intentions \\
*Square root of AVE (in bold)
\end{tabular}

the stimulus for their loyalty towards the restaurant brands because of high involvement and enough attention towards the mobile eWOM.

Considering the third finding, mobile eWOM positively influence perceived quality which is a cognitive response component of S-O-R framework, (.75). The positive assessment of this type of communication is suggested by those consumers who are reliable and trustworthy, diminishes their brand-switching behavior. These findings are in line with previous research (Godey et al. 2016; Kim and Johnson 2016; Wang et al. 2013). Furthermore, findings reveal that brand awareness/association (.17), loyalty (.570) and brand perceived quality $(.295)$ are positively related to brand attitude towards online fast-causal restaurants. This positive relationship to be in accordance with the hypothesized effect of eWOM on brand awareness/ association, brand loyalty and brand perceived quality discussed in previous researches (Godey et al. 2016; Schivinski and Dabrowski 2015). Prendergast et al. (2016) also found that positive, negative, or mixed eWOM valence affect perceived trust in terms of gender difference, which in turn results positive brand attitude. Finally, we also find the linkage between brand attitude and purchase intention (.79), showing that consumer attitude towards brand and purchase intention are consistent. This finding indicates that brand attitude promoted through mobile eWOM services directly influence consumer response which is in line with previous studies (Wang et al. 2013).

This research contributes to prior literature by providing a holistic framework that demonstrates how mobile eWOM promotes dimensions of CBBE in fastcausal restaurant industry in Indonesia. Prior studies discovered the importance of eWOM and mobile eWOM elements (Godey et al. 2016; Kim and Ko 2012; Wang et al. 2013; Wang et al. 2015), but our empirical study details the relative importance of four elements of mobile eWOM which should be holistically taken into account when planning social media acti- 
Table 4. Standardized structural coefficients of the model

\begin{tabular}{lcccc}
\hline Hypothesis & $\beta$ & C.R & $\begin{array}{c}\mathrm{p}- \\
\text { value }\end{array}$ & $\begin{array}{c}\text { Out } \\
\text { put }\end{array}$ \\
\hline 1.MeWOM $\longrightarrow$ Awareness & $.89^{* * *}$ & 9.66 & $<.001$ & + \\
2.MeWOM $\longrightarrow$ Loyalty & $.77^{* * *}$ & 9.61 & $<.001$ & + \\
3.MeWOM $\longrightarrow$ P.Quality & $.75^{* * *}$ & 8.65 & $<.001$ & + \\
4.Awareness $\longrightarrow$ Attitude & $.17^{* * *}$ & 2.46 & $<.001$ & + \\
5.Loyalty $\longrightarrow$ Attitude & $.57^{* * *}$ & 4.58 & $<.001$ & + \\
6.P.Quality $\longrightarrow$ Attitude & $.29^{* * *}$ & 3.24 & $<.001$ & + \\
7.Attitude $\longrightarrow$ PI & $.79^{* * *}$ & 8.64 & $<.001$ & + \\
8.MeWOM $\rightarrow$ CBBE $\rightarrow$ PI & \multicolumn{4}{c}{ Full Mediation } \\
\hline *** p<.001 \\
Note: MeWOM=Mobile electronic word of mouth. \\
P.Quality = Perceived Quality.
\end{tabular}

vities on mobile. The results are also consistent across online fast-causal restaurant industry.

Another contribution to study is that it finds out the positive effect of mobile eWOM dimensions of CBBE. This result means that mobile eWOM should not only be thought of as a means of raising brand association, brand loyalty and reaching new customers, but also as an increasingly important and serious brand image building tool in terms of brand perceived quality.

Finally, the study is the first to detail how mobile eWOM influences CBBE and, consequently, consumer response in fast-causal restaurant industry in Indonesia. Not only our results indicated that CBBE affects overall consumer responses positively, which is consistent with previous work on CBBE (Godey et al. 2016; Wang et al. 2015), but also that CBBE serves as a full mediator of mobile eWOM and consumer response (See Table 4). This result suggests that investments in CBBE would strengthen mobile eWOM efforts on customer responses.

\section{Implications}

The findings of the study attempted to provide the theoretical and practical implication. Model adopted in this study brings a new approach to information adoption by extending S-O-R framework which provides new insight for Information Systems researchers. This study contributes to the future research by empirically testing mobile eWOM studies arguments (Wang et al. 2013), which suggests the joint evaluation of characteristics of mobile eWOM information and consumers' behavior towards mobile eWOM information. This study also provides a greater understanding of mobile eWOM on SNS by highlighting the determinants of mobile eWOM information on SNS, influences consumers purchase intentions in CBBE context.

From a managerial perspective, this study provides marketers with a frame work to develop the understan- ding of impact of mobile eWOM on consumers' behavior in SNS context. Mobile convenience is the most significant differentiating attribute of mobile eWOM, is required to form the users' positive attitude. This attribute must be considered in terms of time, space, ease-of-use and design (Ström et al. 2014). In fact, users may hesitate to use the mobile communications network because of limitations in these attributes. It is important for managers to have an interface, designed to overcome these limitations. Mobile SNS has a positive impact on hedonic generation. The design of mobile platforms should be enhanced in order to feel the sense of closeness and enjoyment. The determinants of mobile eWOM provided by this study are practically very important which allow marketers to understand the dynamics of mobile eWOM on social media, and thus to develop better marketing strategies.

\section{Limitations and recommendations for future research}

This study has several limitations that can be addressed in future research. The main limitation of the study is its generalizability beyond the restaurant indutry. While the results are likely to be useful in fastcausal restaurant sector, they may not be directly applicable to other industries. Future research can be applied at different situational contexts (e.g., intentional visit to brand fan pages) as well as a range of service categories (e.g. healthcare, entertainment, tourism etc.) that vary in terms of service attributes (e.g., hedonic, utilitarian) so that the model of consumer response to mobile eWOM can be validated/modified as needed.

Second, this research depends only on group of respondents in Indonesian city of Jakarta; since the survey participants are not representative of all mobile SNS users in Indonesia. However, future research on mobile eWOM can collect data from other groups (non mobile app users) and other cities of Indonesia. Researchers should evaluate the cross-country comparisons to identify the best strategic configurations to achieve the best performance.

Third, socio-demographic variables such as age, gender, income, and education, might have a significant moderating effect, on the conceptual model. It may be fruitful to assess these variables as moderators in future for a more thorough understanding of the studied phenomenon. Finally, the study sample size was not large enough to explore the effect of mobile eWOM and consumer behavior. This short coming can be addressed in future research. Longitudinal study can be conducted in future to keep track of changes in digital environment. 


\section{Appendix A. Measure of constructs}

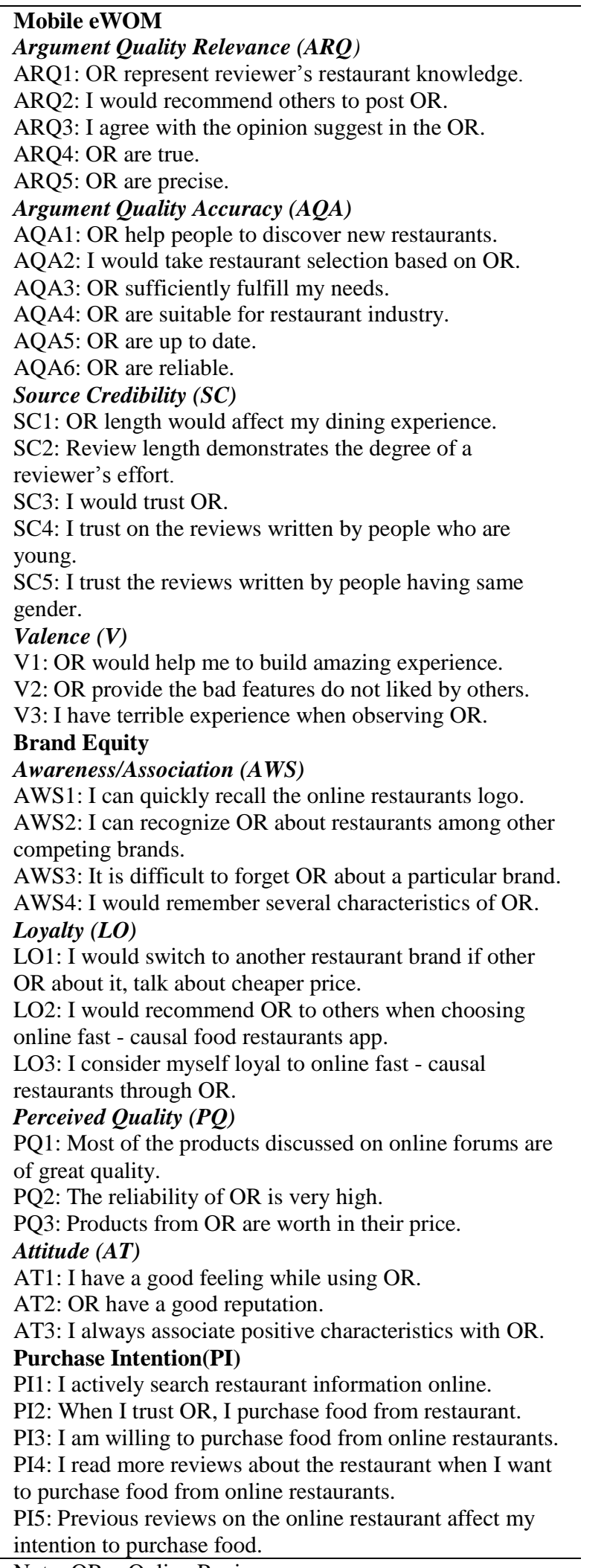

\section{Acknowledgments}

This research is supported by the National Natural Science Foundation of People's Republic of China (No.71531013, 71401047, 71729001).

\section{References}

[1] Allen Broyles, S., Leingpibul, T., Ross, R.H.,and Foster, B.M.,"Brand Equity's Antecedent/Consequence Relationships in Cross- Cultural Settings", Journal of Product \& Brand Management(19:3), Emerald insight, http://doi.org/10.1108/1 0610421011046148, 2010, pp. 159-169.

[2] Ayeh, J.K., Au, N., and Law, R.,"Predicting the Intention to Use Consumer-Generated Media for Travel Planning", Tourism Management(35),Elsevier,http://dx.doi.org/10.1016/ j.tourman.2012.06.010,2013,pp.132-143.

[3] Baron, R. M., \& Kenny, D. A. "The moderator-mediator variable distinction in social psychological research: conceptual, strategic and statistical considerations". Journal of Personality and Social Psychology, American Psychological Association, 1986, 1173-1182.

[4] Baxendale,S.,Macdonald, E.K., and Wilson, H.N.,"The Impact of Different Touchpoints on Brand Consideration", Journal of Retailing,(91:2), Elsevier, http: //dx.doi.org/10.101 6/j.jretai.2014.12.008, 2015, pp.235-253.

[5] Bruhn, M., Coulter, K.S., Schoenmueller, V., and Schäfer, D.B.,"Are Social Media Replacing Traditional Media in Terms of Brand Equity Creation?", Management Research Review (35:9), Emerald insight, http://dx.doi.org /10.1108/01409171211255948, 2012, pp.770-790.

[6] Buil, I., Martínez, E., and de Chernatony, L., "The Influence of Brand Equity on Consumer Responses, "Journal of Consumer Marketing (30:1)", Emerald insight, http://doi.o rg/10.1108/07363761311290849,2013,pp.62-74.

[7] Chebat, J.-C., and Michon, R.,"Impact of Ambient Odors on Mall Shoppers' Emotions, Cognition, and Spending", Journal of Business Research (56:7), Elsevier, doi:10.1016/S 01482963(01)00247-8, 2003, pp. 529-539.

[8] Cheung,C.M.K., and Thadani,D.R. 2012.,"The Impact of EWOM Communication:A Literature Analysis and Integrative Model",Decision Support Systems,Elsevier(54:1),http://dx doi.org/10.1016/j.jretconser.2013.12.003,2013,pp.461-470.

[9] Erkan, I., and Evans, C., "The Influence of Ewom in Social Media on Consumers' Purchase Intentions: An Extended Approach to Information Adoption", Computers in Human Behavior (61), Elsevier, http://dx.doi.org/10.1016/j.c hb.2016.03.003, 2016, pp. 47-55.

[10] Eroglu,S.A.,Machleit, K.A., and Davis, L.M.,"Empirical Testing of a Model of Online Store Atmospherics and Shopper Responses, "Psychology and Marketing (20:2), Wiley Inter Science, DOI:10.1002/mar.10064,2003,pp. 139-150.

[11] Godey, B., Manthiou, A., Pederzoli, D., Rokka, J., Aiello, G., Donvito, R., and Singh, R.,"Social Media Marketing Efforts of Luxury Brands: Influence on Brand Equity and Consumer Behavior", Journal of Business Research(69:12),Elsevier,http://dx.doi.org/10.1016/j.jbusres. 2016.04.181,2016,pp. 5833-5841.

[12] Gupta, A., and Arora, N.,"Understanding Determinants 
and Barriers of Mobile Shopping Adoption Using Behavioral Reasoning Theory, "Journal of Retailing and Consumer Services(36), Elsevier, http://dx.doi.org /10.1016/j.jretconser. 2016.12.012,2017, pp. 1-7.

[13] Ha, Y.W., Kim, J., Libaque-Saenz, C.F., Chang, Y., and Park, M.-C.,"Use and Gratifications of Mobile Snss: Facebook and Kakaotalk in Korea", Telematics and Informatics(32:3),Elsevier,http://dx.doi.org/10.1016/j.tele.20 14.10.006, 2015, pp. 425-438.

[14] Hsiao, C.-H., Chang, J.-J., and Tang, K.-Y., "Exploring the Influential Factors in Continuance Usage of Mobile Social Apps: Satisfaction, Habit, and Customer Value Perspectives," Telematics and Informatics (33:2),Elsevier, http:// dx.doi.org/10.1016/j.tele.2015.08.014, 2016, pp. 342-355.

[15] Hudson, S., Roth, M.S., Madden, T.J., and Hudson, R., "The Effects of Social Media on Emotions, Brand Relationship Quality, and Word of Mouth: An Empirical Study of Music Festival Attendees", Tourism Management (47), Elsevier, http://dx.doi.org/10.1016/j.tourman.2014.09.001, 2015, pp. 68-76.

[16] Jeong,E.,and Jang,S. 2011.,"Restaurant Experiences Triggering Positive Electronic Word-of-Mouth (Ewom) Motivations, "International Journal of Hospitality Management(30:2) ,Elsevier,doi:10.1016/j.ijhm.2010.08.005, 2011, pp. 356-366. [17] Kim, A.J., and Johnson, K.K.P., "Power of Consumers Using Social Media: Examining the Influences of BrandRelated User-Generated Content on Facebook, "Computers in Human Behavior (58), Elsevier, http://dx.doi.org/10. 1016 /j.chb.2015.12.047, 2016, pp. 98-108.

[18] Kim,A.J.,and Ko, E.,"Do Social Media Marketing Activities Enhance Customer Equity?An Empirical Study of Luxry Fashion Brand",Journal of Business Research,Elsevier (65, :10),doi:10.1016/j.jbusres.2011.10.014,2012, pp. 1480-1486.

[19] Lin, Y.-H., Hsu, C.-L., Chen, M.-F., and Fang, C.H.,"New Gratifications for Social Word-of-Mouth Spread Via Mobile Snss: Uses and Gratifications Approach with a Perspective of Media Technology", Telematics and informatics(34:4),Elsevier,http://dx.doi.org/10.1016/j.tele.2016.08.01 9,2017, pp. 382-397.

[20] López,M.,and Sicilia,M.,"Determinants of E-Wom Influence:The Role of Consumers' Internet Experience", Journal of theoretical and applied electronic commerce research (9:1),doi:10.4067/S071818762014000100004,2014, pp. 7-8.

[21] Lu,Y.,Yang, S., Chau, P.Y.K., and Cao, Y.,"Dynamics between the Trust Transfer Process and Intention to Use Mobile Payment Services: A Cross-Environment Perspective", Information \& Management (48:8), Elsevier, doi:10.1016/ j.im.2011.09.006, pp. 393-403.

[22] Murtiasih, S., Sucherly, and Siringoringo, H., "How of Mouth Influence Brand Equity for Automotive Products in Indonesia",Procedia-Social and Behavioral Sciences(81), Elsevier,doi:10.1016/j.sbspro.2013.06.384,2013,pp.40-44.

[23] Park, M.-S.,Shin, J.-K., and Ju, Y.,"The Effect of Online Social Network Characteristics on Consumer Purchasing intention of Social Deals", Global Economic Review(43:1), The Review of Marketing Communication, http://dx.doi.org/10.1 080/1226508X.2014.884047,2014, pp. 25-41.
[24] Prendergast, G., Paliwal, A., and Chan, K.K.F., "Trust in Online Recommendations: An Evolutionary Psychology Perspective", International Journal of Advertising, The Review of Marketing Communication, http://dx.doi.org/10. 1080/02650487.2016.1239879, 2016, pp.1-17.

[25] Rios, R.E., and Riquelme, H.E., "Brand Equity for Online Companies", Marketing Intelligence \& Planning (26:7), Emerald insight, http://dx.doi.org/10.1108/026345008 10916681, 2008, pp. 719-742.

[26] Ryu , K., Han, H., and Jang, S., "Relationships among hedonic and utilitarian values, satisfaction and behavioral intentions in the fast-casual restaurant industry", International Journal of Contemporary Hospitality Management, Emerald insight,doi:10.1108/0959611101103981,2010, pp.416-432.

[27] Schivinski,B., and Dabrowski, D., "The Impact of Brand Communication on Brand Equity through Facebook",Journal of Research in Interactive Marketing, Emerald insight, http://dx.doi.org/10.1108/JRIM-02-20140007,2015,pp.31-53. [28] Shekhar Kumar, R., Malhotra, N., Dash, S., and Chandra Purwar, P.,"The Nature and Antecedents of Brand Equity and Its Dimensions", Marketing Intelligence \& Planning, Emerald insight, https://doi.org/10.1108/0263450131131204 4, 2013, pp. 141-159.

[29] Shuv-Ami, A.,"A New Market Brand Equity Model (Mbe)",EuroMed Journal of Business (11:3),Emerald Insight, https://doi.org/10.1108/EMJB-0520150025,2016,pp.322-346. [30] Sparks, B.A., and Browning, V.,"The Impact of Online Reviews on Hotel Booking Intentions and Perception of Trust, "Tourism Management, Elsevier, doi:10.1016/j.tourma n.2010.12.011, 2011,pp. 1310-1323.

[31] Ström, R., Vendel, M., and Bredican, J.,"Mobile Marketing: A Literature Review on Its Value for Consumers and Retailers", Journal of Retailing and Consumer Services (21:6),Elsevier,http://dx.doi.org/10.1016/j.jretconser.2013.12 $.003,2014$, pp. 1001-1012.

[32] Wang, N., Shen, X.-L., and Sun, Y., "Transition of Electronic Word-of-Mouth Services from Web to Mobile Context: A Trust Transfer Perspective, "Decision Support Systems (54:3), Elsevier, http://dx.doi.org/10.1016/j.dss.2012 .12.015,2013, pp. 1394-1403.

[33] Wang, R.J.-H., Malthouse, E.C., and Krishnamurthi, L.,"On the Go: How Mobile Shopping Affects Customer Purchase Behavior,"Journal of Retailing (91:2), Elsevier, http://dx.doi.org/10.1016/j.dss.2012.12.015,2015,pp.217-234. [34] Wang, Y.J., Minor, M.S., and Wei, J., "Aesthetics and the Online Shopping Environment: Understanding Consumer Responses, "Journal of Retailing (87:1), Elsevier,doi:10.1016 /j.jretai.2010.09.002,2011, pp. 46-58.

[35] World Population Review (2017). Jakarta Population. Retrieved from http://worldpopulationreview.com/worldcities/jakarta-population/.

[36] Xie, K.L., Zhang, Z., and Zhang, Z. "The Business Value of Online Consumer Reviews and Management Response to Hotel Performance, "International Journal of Hospitality Management (43), Elsevier, http://dx.doi.org/ 10.1016/j.ijhm.2014.07.00,2014, pp. 1-12. 